\title{
Some Inflammatory and Endothelial Dysfunction Biomarker levels in Obese Pre-pubertal Children
}

\author{
Elnashar. NA ${ }^{1}$, Elhosary AA ${ }^{2}$, Elnashar. MA $^{3}$ and Mohamed HA ${ }^{1}$ \\ ${ }^{I}$ Pathology Department Faculty of medicine, Taif University, Saudi Arabia. \\ ${ }^{2}$ Clinical pathology Department, Faculty of Medicine, Menoufia University, Egypt. \\ ${ }^{3}$ Pediatric Department Faculty of medicine, Taif University, Saudi Arabia
}

\begin{abstract}
Childhood obesity has grown at an alarming rate, and is associated with metabolic disturbances that determine a higher risk of type 2diabetes and atherosclerotic vascular disease in adulthood. These disturbances may arise at a veryearly age in obese children. These metabolic disturbances may be associated with insulinresistance (IR), a systemic low-grade inflammatory state andendothelial dysfunction.

Objective:to determine the concentration levels of some inflammatory markers in obese pre-pubertal children, and their possible relation with metabolic syndrome.

Methods: We analyzed weight $(\mathrm{kg})$, height $(\mathrm{m})$, body mass index $\left(B M I ; \mathrm{kg} / \mathrm{m}^{2}\right)$, systolic and diastolic blood pressure (SBP and DBP/ $\mathrm{mm} \mathrm{Hg}$ ), fasting plasma glucose (FPG), HOMA-IR,CRP,IL-6 and sICAM-1 in 25 obese and 25 non-obese children as a control group.

Results: Obese children displayedsignificantly elevated values for insulin $(p<0.001)$, homeostasis model assessmentfor IR (HOMA-IR; $p<0.001)$, CRP ( $p<0.001)$,IL-6 ( $p<0.001)$ and sICAM-1 levels $(p<0.001)$. Nonsignificantdifferences were found in fasting glucose. In theobese group, sICAM-1 showed a positive correlationwith insulin( $p<0.05)$, HOMA-IR ( $p<0.0001)$ and CRP $(p<0.05)$ and IL-6 ( $p<0.05)$.

Conclusion: Pre-pubertal obese children displayed alterations indicative of insulin resistance, endothelial dysfunction and inflammatory state whichmay increase dangerous of CVD and type 2 DM in the future. Thus, early identification of the inflammatory and endothelial biomarkers in obese children may assist in early interference to prevent progression and complications of type 2 DM and CVD. Moreover, longitudinal studies are needed to recognize the requirement of giving anti-inflammatory drugs to reduce inflammation in the children who are proposed to be diabetics.
\end{abstract}

Keywords: Childhood obesity, metabolic syndrome, insulin resistance and endothelial dysfunction

\section{Introduction}

Obesity is the most prevalent nutritional disorder among children and adolescents. Its prevalence has increased so significantly in recent years that many consider it a major health concern of the developed world [1].Childhood obesity has more than doubled in children and quadrupled in adolescents in the past 30 years [2] and has been known as a major risk factor for insulin resistance in children with metabolic syndrome [3]. The increasing incidenceof childhood obesity and the earlier onset of insulinresistance, hypertension, and dyslipidemia increased risk factors forcardiovascular disease. These metabolic abnormalities in children may predict that diabetesand cardiovascular disease complications may appear earlier than previously thought $[3,4]$. The pathogenesis of obesity-related insulin resistance and type 2 diabetes involve chronic low-grade inflammation and production of inflammatory cytokinescontributing tovascular reactivity,endothelial dysfunctionanddiabetic vascular complications[5]. In presence of obesity different tissues including the adipose tissue itself are sites of inflammation. An infiltration of macrophages and other immune cells is observed in these tissues associated with a cell population shift from an anti-inflammatory to a pro-inflammatory profile. Actually these cells are endocrine cells which produces a large number of bioactive proinflammatory and prothrombotic adipokines [6], which interfere with insulin signaling in peripheral tissues or induce $\beta$-cell dysfunction and subsequent diabetes and metabolic syndrome [7].

The presence of inflammation in both obesity and metabolic syndrome may by caused by Toll-like receptors (TLRs)stimulationmostly by activation of TLR 2 and TLR4. TLRs, especially TLR4, are activated by fatty acids released from the adipose tissue and circulating endotoxinemia (a marker of gut permeability or excess circulatinggut derived bacteria)[8] resulting in activation of nuclear factor- $\mathrm{kB}$ and increased release of inflammatory biomediatorslike CRP [9], IL-6, IL-1 $\beta$, TNF- $\alpha$, and monocyte chemotactic protein-1 [10]. The metabolic syndrome and type 2 diabetes are associated with endothelial activation. Endothelial dysfunction represents an early phase of vascular changes that eventually lead to atherosclerosis with all its unfavorable complications [11]. The sICAM-1 plays an important role in the initiation of the inflammatory process and is a biochemical marker associated with atherosclerotic progression and with other inflammatory disease processes [12]. Elevated levels of this molecule are indicative of endothelial dysfunction and imply enhanced leukocyte 
adhesion to the endothelium [13], a physiopathologically decisive stage in atherogenesis [14]. Diagnosis of metabolic syndrome was defined according to the National Institutes of Health (1998)[15] criteria adapted for children. As in adults, children areclassified as having the metabolic syndrome if they meet threeor more of the following criteria for age and gender. BMI above the 95th percentile [16], triglyceridelevel above the 95th percentile, HDL- cholesterol below the 5th percentile, systolic or diastolic blood pressure abovethe 95th percentile, impaired fasting glucose or impaired glucose tolerance (IGT) as defined by the AmericanDiabetes Association [17].Thus the objective of this study is toinvestigate the relationship of inflammatory markers and markers of endothelial dysfunction with both IR and inflammation in pre-pubertal obese children and their possible relation with metabolic syndrome.

\section{Subjects And Methods}

2.1 Subjects: A case-control study was carried out on 50 children of both sexes. These children were divided into two groups. The first group included 25 obese children (17boys and 8 girls), body mass index (BMI) over percentile 95 in growth curves. These patients were attending the pediatric outpatient clinic, King AbdElaziz Hospital. The other (control group) comprised 25non-obese children (percentile < 85) matching by age $(6-10$ years) and sex (13 boys and 12 girls).

An informed phrasal consent from the parent of each participant was obtained.

Exclusion criteria: The children with; symptoms of infection during the 2 weeks before the study, family history for cardiovascular diseases or diabetes, cardiovascular abnormalities, diabetes, primary hyperlipidemiaand secondary obesity andany child receiving pharmacological treatment.

2.2 Collection of Blood samples: Twovenous blood samples were collected. The first one (2ml) was collectedover EDTA after 8 hours fasting and assayed immediately for the determination of fasting plasma glucose and plasma insulin. The other Venous blood sample $(8 \mathrm{ml})$ was collectedafter 14 hours fasting for measuring lipid profile and inflammatory markers. Serum of the second sample was separated, divided into aliquots and preserved at $-20^{\circ} \mathrm{C}$ until used.

\subsection{Biochemical measurements:}

1. Fasting plasma glucose (FPG)was determined by enzymatic method according to Trinder [18].

2. Fasting plasma insulin was quantified using radioimmunoassay systemdescribed by Buritus and Ashwood [19]. The homeostasis model assessment for IR (HOMA-IR) was used to detect the degree of insulin resistance. Resistance was assessed from fasting glucose and insulin concentrations using the formula: HOMA-IR = Insulin $(\mu \mathrm{U} / \mathrm{ml}) \times$ blood glucose $(\mathrm{mg} / \mathrm{dl}) / 405$ [20].

3. C-reactive protein (CRP) was measured by the semi-quantitative latex agglutination assay (Humatex CRP, Human Gesellschft fur Biochemica und DiagnosticambH, D-65205 Wiesbaden, Germany).

4. s-ICAM- 1 was analyzed as a single determination by commercial assays using enzyme linked immune sorbent assay (ELISA) kit[17].

5. IL-6 was measured using commercially available ELISA kits according to the manufacturer's instructions (PharmingenInc, San Diego, Calif) for the quantitative measurement of human IL-6 in serum[18].

6. Serum total cholesterol and triglycerides[19], were measured by routine colorimetric method using commercial assay kits supplied by Bicon Co. (Germany). While HDL- cholesterol and, LDL-cholesterol were measured by precipitation technique described by Lopes-Virella et al.,[20] and Rifai et al., [25] respectively.

2.4 Anthropometric measurements:Body mass index [BMI (weight in $\mathrm{kg} / \mathrm{height} 2 \mathrm{in} \mathrm{m}$ )] was calculated. to distinguish overweight and obese children, overweight $(\geq 85 \%$ to $<95 \%)$ or obese $(\geq 95 \%)$ according to the National Center for Health Statistics criteria. Only obese children were included in this study [16].

2.5 Statistical analysis: Results were expressed as mean \pm SD. The mean values of the groups were compared using Student's unpaired t-test. Statistical significance was set at $\mathrm{P}<0.05$. Correlation between variables was evaluated using Pearson's correlation coefficient and regression analysis.

\section{Results}

3.1 Anthropometric data and selected biochemical parameters: The characteristics of obese and control group children are listed in Table 1. The prevalence of obesity was higher in boys as compared to girls (56.6 vs. $43.3 \%) .18$ obese children $(60 \%)$ were recorded to be hypertensive and $12(40 \%)$ had hyperinsulinemia and were insulin resistant. The two groups did not differ significantly in age, gender, and height. The mean BMI was $25.46 \pm 2.77 \mathrm{~kg} / \mathrm{m} 2$ in the obese group and was $17.43 \pm 0.97 \mathrm{~kg} / \mathrm{m} 2$ in the control group; the difference was statistically significant. Between obese and non-obese children, distributions of the blood pressure readings differed significantly for systolic blood pressure $(\mathrm{P}<0.05)$ and it showed a positive correlationwith BMI $(\mathrm{P}=0.022)$ (figure 1).Fasting glucose showed a non-significant increase in the obese group, while the mean for 
insulin and HOMA for insulin resistance (HOMA-IR) index showed a significant increase in the obese compared to the non-obese group $(\mathrm{P}<0.001)$.

3.2 Comparison of Lipid profile and inflammatory biomarkers: Mean LDL-C and triglycerides were significantly higher in obese children $(109.17 \pm 12.05,82.07 \pm 17.78 \mathrm{mg} / \mathrm{dl}$ versus $90.4 \pm 10.77,51.6 \pm 6.92$ respectively). CRP concentrations were significantly higher in obese children $(2.13 \pm 0.90 \mathrm{mg} / \mathrm{dl}$ obese versus $0.95 \pm 0.39 \mathrm{mg} / \mathrm{dl}$ control). Serum IL-6 levels were also significantly higher in the obese group than the control group ( $<$ 0.001). Mean sICAM-1 levels were significantly higher in obese children at $267.28 \pm 31.00 \mathrm{ng} / \mathrm{ml}$ compared with $231.01 \pm 20.13 \mathrm{ng} / \mathrm{ml}$ in the non-obese group (table 2).

3.3 Correlation involving insulin and HOMA-IR with BMI and lipid profile: There were positive correlations linking insulin and HOMA-IR with BMI, systolic blood pressure, LDL-Cand triglycerides.in addition a negative correlationbetween insulin and HOMA-IRwith HDL-Cwas noticed (table3).

3.4 Correlation of metabolic syndrome parameters with CRP, IL-6 and sICAM: In the multiple regression analysis for the obese group.Table 4 displays that BMI correlated positively with CRP, IL-6 and sICAM-1. Also sICAM-1 concentration was positively correlated with systolic blood pressure. Moreover, insulin and HOMAIR index was positively correlated with CRP, IL-6 and sICAM-1.

3.5 regression analysisbetween CRP, IL-6 and sICAM:figure 2displays Serum CRP concentrations as a function of IL-6 and figure 3displays Serum sICAM-1 concentrations as a function of CRP in obese children.

Table (1): Anthropometric data and selected biochemical parameters for obese and control groups

\begin{tabular}{|l|l|l|l|}
\hline Parameters & Obese group(n=30) & Non-obese group $(\mathbf{n}=\mathbf{2 0})$ & *p- value \\
\hline age & $7.95 \pm 1.2$ & $8.25 \pm 1.0$ & NS \\
\hline Sex(M/F) & $(16 / 14)$ & $(12 / 8)$ & \\
\hline Weight $(\mathbf{k g})$ & $37.45 \pm 4.75$ & $25.29 \pm 3.06$ & $<0.001$ \\
\hline Height $(\mathbf{c m})$ & $127.61 \pm 6.65$ & $126.8 \pm 8.5$ & $\mathrm{NS}$ \\
\hline BMI $\left(\mathbf{k g} / \mathbf{m}^{2}\right)$ & $25.46 \pm 2.77$ & $17.43 \pm 0.97$ & $<0.001$ \\
\hline SBP(mm Hg) & $115.04 \pm 6.11$ & $105.2 \pm 5.92$ & $<0.05$ \\
\hline DBP(mm Hg) & $70 \pm 9$ & $69.9 \pm 9.4$ & $\mathrm{NS}$ \\
\hline Fasting glucose (mg/d) & $82.5 \pm 8.90$ & $80.2 \pm 12.60$ & $\mathrm{NS} \mathrm{N}$ \\
\hline Fasting insulin $(\square \mathbf{U} / \mathbf{m l})$ & $18.36 \pm 3.28$ & $10.99 \pm 2.07$ & $<0.001$ \\
\hline HOMA-IR & $3.97 \pm 0.67$ & $2.28 \pm 1.23$ & $<0.001$ \\
\hline
\end{tabular}

BMI, body mass index; SBP, systolic blood pressure ; DBP, diastolic blood pressure, HOMA-IR, homeostasis model assessment for insulin resistance

$* \mathrm{P}$ values $<0.05$ were considered as significant.

$* \mathrm{P}$ values $<0.001$ were considered as highly significant.

$* \mathrm{P}$ values $<0.0001$ were considered as very highly significant.

Table (2): Comparison of Lipid profile and inflammatory biomarkers values between obese children $\&$ nonobese children

\begin{tabular}{|l|l|l|l|}
\hline Parameters & Obese group & Non-obese group & p value \\
\hline Total cholesterol (mg/dl) & $175.23 \pm 17.30$ & $169.13 \pm 12.40$ & NS \\
\hline HDL-C (mg/dl) & $30.93 \pm 3.50$ & $49.47 \pm 4.68$ & $<0.001$ \\
\hline LDL-C $(\mathbf{m g} / \mathbf{d l})$ & $109.17 \pm 12.05$ & $90.4 \pm 10.77$ & $<0.001$ \\
\hline Triglycerides (mg/dl) & $82.07 \pm 17.78$ & $51.6 \pm 6.92$ & $<0.001$ \\
\hline CRP $(\mathbf{m g} / \mathbf{d l})$ & $2.13 \pm 0.90$ & $0.95 \pm 0.39$ & $<0.001$ \\
\hline IL- $\mathbf{~ ( p g / m l ) ~}$ & $46.52 \pm 7.17$ & $12.77 \pm 2.94$ & $<0.001$ \\
\hline sICAM-1 (ng/ml) & $267.28 \pm 31.00$ & $231.01 \pm 20.13$ & $<0.001$ \\
\hline
\end{tabular}

HDL-C, high-density lipoproteins cholesterol; LDL-C, low-density lipoproteins cholesterol; CRP, C- reactive protein ; IL- 6, Interleukin 6 and sICAM-1, solubleintercellular adhesion molecule-1

Table (3): Correlation involving insulin and HOMA-IR with BMI and lipid profile in obese children.

\begin{tabular}{|l|c|l|r|l|}
\hline \multirow{2}{*}{} & \multicolumn{2}{|l|}{ Insulin } & \multicolumn{2}{l|}{ HOMA-IR } \\
\cline { 2 - 5 } & $\mathrm{r}$ & $\mathrm{p}$ & $\mathrm{r}$ & $\mathrm{p}$ \\
\hline BMI & 0.381 & $<0.05$ & 0.445 & $<0.05$ \\
\hline SBP & 0.865 & $<0.0001$ & 0.760 & $<0.001$ \\
\hline HDL-C & -0.799 & $<0.0001$ & -0.638 & $<0.0001$ \\
\hline LDL-C & 0.435 & $<0.05$ & 0.539 & $<0.001$ \\
\hline Triglyceride & 0.365 & $<0.05$ & 0.551 & $<0.001$ \\
\hline
\end{tabular}


Table (4): Correlation of metabolic syndrome parameters with CRP, IL-6 and sICAM in obese children.

\begin{tabular}{|l|l|l|l|l|r|r|}
\hline & \multicolumn{2}{l|}{ CRP } & \multicolumn{2}{l|}{ IL-6 } & \multicolumn{2}{l|}{ sICAM } \\
\cline { 2 - 8 } & $\mathrm{r}$ & $\mathrm{p}$ & $\mathrm{r}$ & $\mathrm{p}$ & $\mathrm{r}$ & $\mathrm{p}$ \\
\hline BMI & 0.412 & $<0.05$ & 0.896 & $<0.0001$ & 0.632 & $<0.001$ \\
\hline SBP & 0.021 & $\mathrm{NS}$ & 0.165 & $\mathrm{NS}$ & 0.494 & $<0.0001$ \\
\hline HDL-C & -0.786 & $<0.0001$ & -0.259 & $\mathrm{NS}$ & -0.396 & $<0.05$ \\
\hline LDL-C & 0.545 & $<0.001$ & 0.244 & $\mathrm{NS}$ & 0.329 & $<0.001$ \\
\hline Insulin & 0.885 & $<0.0001$ & 0.747 & $<0.0001$ & 0.374 & $<0.05$ \\
\hline HOMA-IR & 0.691 & $<0.0001$ & 0.842 & $<0.0001$ & 0.666 & $<0.0001$ \\
\hline
\end{tabular}

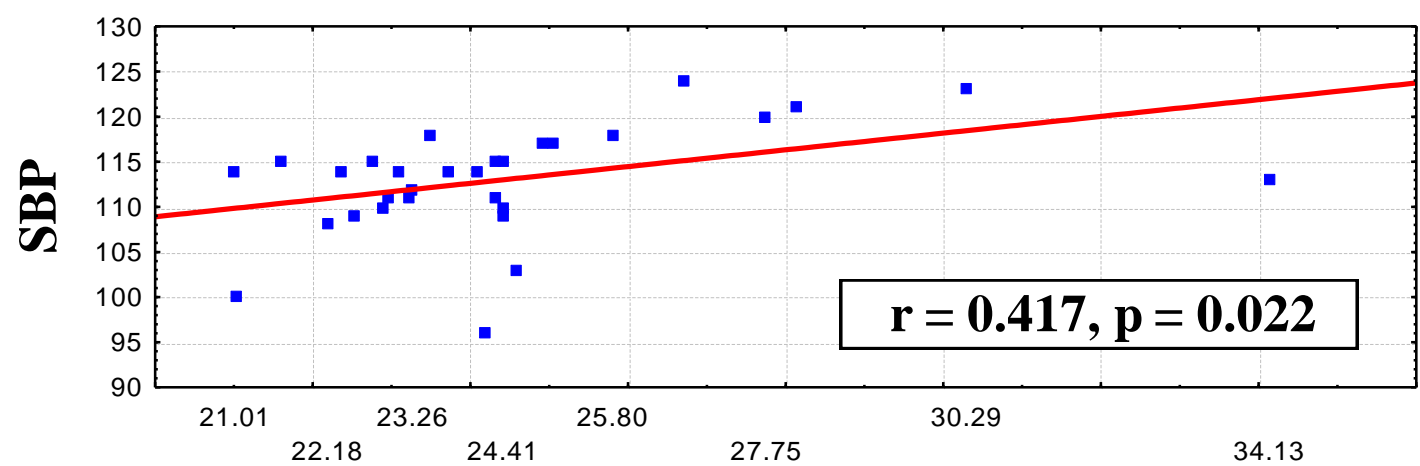

$\operatorname{BMI}\left(\mathrm{kg} / \mathrm{m}^{2}\right)$

Figure 1 : Correlation between body mass index and systolic blood pressure in obese children

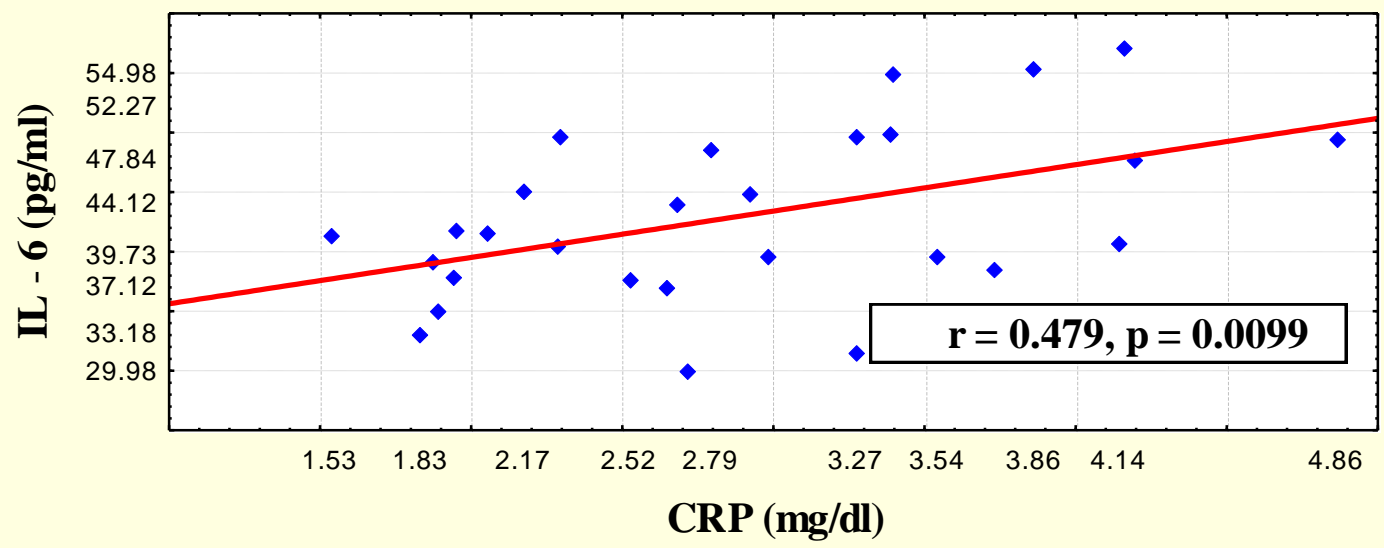

Figure 2: Serum CRP concentrations as a function of IL-6
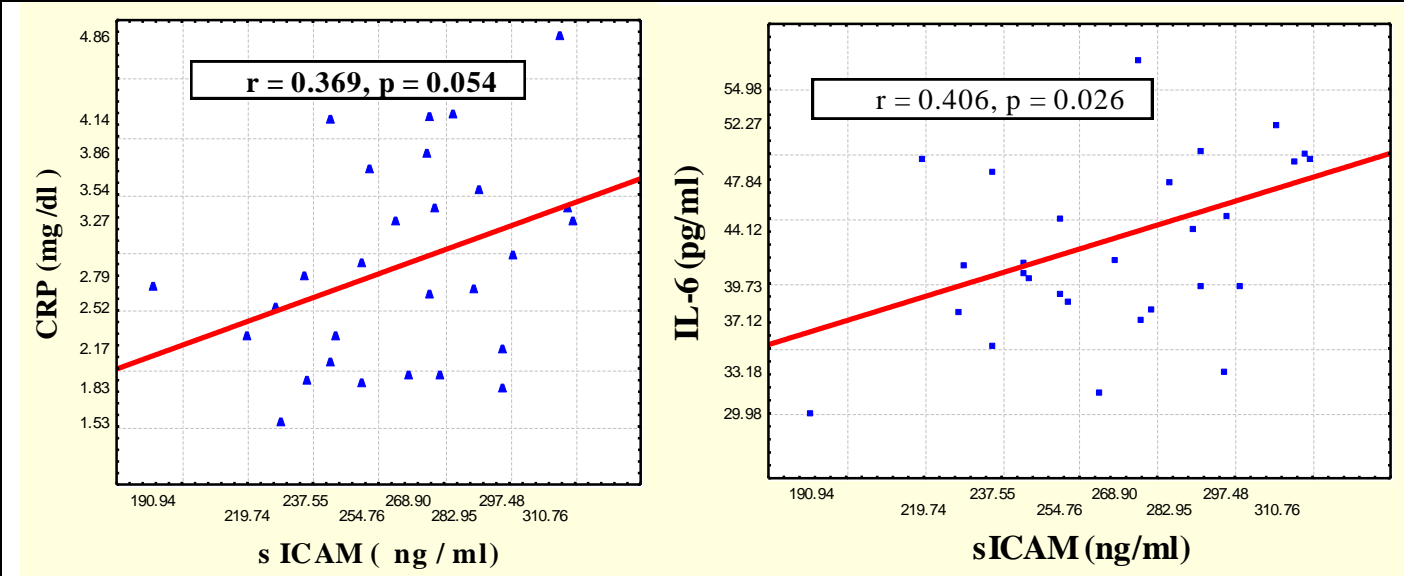

Figure 3: Serum sICAM-1 concentrations as a function of CRP in obese children. 


\section{Discussion}

Childhood obesity has grown at an alarming rate, and as it plays a central role indevelopment of metabolic syndrome; it has been turned into a modern worldwide epidemic and has become a well-recognised risk factor of cardiovascular disorders and diabetes mellitus [26]. Hyperinsulinemia and insulin resistance have been involved in vascular reactivity and a growing evidence suggested the role of low grade inflammation as a link between obesity, insulin resistance and endothelial dysfunction [5].Clustering of at least three of elevated blood glucose, obesity, high blood pressure, elevated triglycerides and low high density lipoprotein (HDL) cholesterol is defined as metabolic syndrome[15].All of these arewell established risk factors in the development of coronary artery disease[6].

This study showed a positive correlation between HOMA-IR and BMI with a highly significant difference in the two variable between obese and non-obese children. This findingvalidate thatobesityrepresent a major risk factor for the developmentof insulin resistance in children and adolescents which can be an importantlink between obesity and the associated metabolic abnormalitiesandcardiovascular risk. SimilarlyEckel et al.[27]andMorrison et al. [28] had found the same finding.Morrison et al. stated also that the interaction of BMI with HOMA-IR can open routes for intervention to reduce or even prevent the risk of metabolic syndrome later in early adulthood life [28]. Emphasizing that HOMA index is validated as a reliablemeasure of insulin sensitivity in children and that it isstrongly associated with endothelial dysfunction and diabetes, Keskin et al. recommended to use it for identifying high-risk children and to take into consideration early preventive measures fordiabetesprevention[29]. The early diagnosis and intervention for prepubertal childreninsulin resistance is very crucial as itmight be further exacerbated by theinfluence of puberty, due to the physiological decrease in insulinsensitivity associated with normal pubertal development and thus leading to the greatest impairment in the parameters considered to be constituents of metabolic syndrome [30].

The presence of low-grade inflammation in obese childrenthat appeared in this studywas evaluated by measuring serumconcentrationsof CRP and IL6, as both showed a highly significant difference compared to the non-obese children and a very strong positive correlation with each other and with HOMA-IR and BMI.In agreement with thisJiménez et al. [31],Sonya et al. [32],Olzaet al.[33], andValle et al. [34]; all affirmed that the levels of these inflammatory markers are elevated in prepubertal obese children and that are associated with insulin resistance with the subsequent possibility of development of diabetes and cardiovascular disease. Additionally, Oliveira et al. [35] agreed this finding and added that CRP is strongly related with metabolic syndrome and its components including insulin resistance in obese youth.Semiz et al. also approved this finding and stated that CRP correlated with BMI and BP which are risk factors for coronary heart disease, supporting the relationship between obesity, inflammation and atherosclerosis [36].IL-6 is an inflammatory cytokine that stimulates the hepatic productionof CRPthis can explain the state ofinflammationassociated with obesity, and could mediate, at least partially,obesity-related insulin resistance [37].

Increased circulating adhesion molecules in patients with obesityplay an important role in the development of endothelialdysfunction/atherosclerosis [38].Since sICAM is one of the molecules acting on the endothelium, therefore, elevated levels of sICAM are indicative of endothelial dysfunction, indicating enhanced leukocyte adhesion which is pathologically pivotalforatherogenesis [13]. Significantly elevated levels of sICAM-1 were found in the obese children of this study with positive correlation with BMI, SBPHOMA-IR and LDL-C and with a negative correlation with HDL-C. A finding reported byNorata et al.agreed with this and declared that the metabolic syndromecomponents already altered in obese children may induce the expression of cell adhesion molecules, promoting atherogenesis and may precipitate acute atherothrombotic events [39]. The positive correlation noted here between sICAM levels and both fasting insulin levels and HOMA-IR denotes that Insulin resistance has alsobeen associated with endothelial dysfunction in obese patients.

Also, this study declared that sICAM-1 is positively correlatedwith both CPR and IL-6 indicating thatInflammation is associated with endothelial dysfunction in obese children and suggesting thatCRP, which appears to be a key sICAM regulatormay be involved in this process [40]. It has been suggested that sICAMmediated endothelial dysfunction is prompted by cytokines secreted in part by adipose tissue [41].Valle et al.reported elevated sICAM and CRP in obese children, but they noted no correlation between the two [34]. On the other hand, Desideri et al. [42] reported an association between the two variables in obese children older than those studied here. Moreover, Jiménez et al. suggested that CRP, IL-6 and ICAM-1 are molecular markers associated with atherosclerosis and its progression [31].

Theobese group in this study showed increased LDL-c levels and decreased HDL-clevels. This finding has been observed in childrenwith central obesity; these changes are dangerous and they have been correlated with cardiovasculardisease in the general population [43].The correlationanalysis in this study further revealed that insulin resistance, CRP and sICAM were positively correlated with LDL-c while negatively correlated with HDL-c. These findings are in accordance with Chang et al., and they highlighted that childhood weight should have special early attention because insulin resistance,inflammation and dyslipidemia increase the risk of cardiovascular disease in adults [44]. 


\section{Conclusion}

In conclusion, prepubertal obese children displayed alterations denoting inflammation and endothelial dysfunction, and also had several risk factors that may cluster together in different combinations defining metabolic syndrome.Thus, early identification of the inflammatory and endothelial biomarkers in obese children may assist in early interference to prevent progression and complications of cardiovascular disease and type 2 diabetes. Moreover, longitudinal studies are needed to recognize the prerequisite of giving anti-inflammatory drugs to reduce inflammation in the children who are proposed to be diabetics.

\section{References}

[1] Inge TH, King WC, Jenkins TM, et al.The effect of obesity in adolescence on adult health status. Pediatrics132(6), 2013,1098-104.

[2] Ogden CL, Carroll MD, Kit BK, and Flegal KM. Prevalence of childhood and adult obesity in the United States, 20112012. Journal of the American Medical Association 311(8), 2014,806-814.

[3] Saffari F, Jalilolghadr S, Esmailzadehha N andAzinfar P. Metabolic syndrome in a sample of the 6- to 16- year-old overweight or obese pediatric population: a comparison of two definitions. TherClin Risk Manag. 8, 2012,55-63.

[4] Deboer MD. Obesity, systemic inflammation, and increased risk for cardiovascular disease and diabetes among adolescents: A need for screening tools to target interventions. Nutrition. 29, 2013,379-386.

[5] Vázquez LA, Pazos F, Berrazueta JR, Fernández-Escalante C, García-Unzueta T, Freijanes J and Amado JA. Effects of changes in body weight and insulin resistance on inflammation and endothelial function in morbid obesity after bariatric surgery. $\mathrm{J}$ ClinEndocrin Metab.90, 2005, 316-322.

[6] Espinola-Klein C, Gori T, Blankenberg S and Munzel T. Inflammatory markers and cardiovascular risk in the metabolic syndrome. Front Biosci.16, 2011,1663-74.

[7] Esser N, Legrand-Poels S, Piette J, Scheen AJ andPaquot N.Inflammation as a link between obesity, metabolic syndrome and type 2 diabetes. Diabetes Res ClinPract.105(2), 2014,141-50.

[8] Varma MC, Kusminski CM, Azharian S, Gilardini L, Kumar S, Invitti C and McTernan PG. Metabolic endotoxaemia in childhood obesity. BMC Obes.3, 2016;3-8.

[9] Choi J, Joseph L and Pilote L. Etiology and Pathophysiology/Obesity Comorbidities Obesity and C-reactive protein in various populations: a systematic review and meta-analysis. Obesity reviews. 14, 2013, 232-244.

[10] Jialal I, Kaur $\mathrm{H}$ and DevarajS.Toll-like receptor status in obesity and metabolic syndrome: a translational perspective. $\mathrm{J}$ ClinEndocrinolMetab. 99(1), 2014,39-48

[11] McSorley PT, Young IS, McEneny J, Fee H and McCance DR (2004): Susceptibility of low-density lipoprotein to oxidation and circulating cell adhesion molecules in young healthy adult offspring of parents with type 2 diabetes. Metab; 53: 755-759.

[12] Kent JW, Comuzzie AG, Mahaney MC, Almasy L, Rainwater D1, VandeBerg JL, MacCluer JW and Blangero J. Intercellular adhesion molecule-1 concentration is genetically correlated with insulin resistance, obesity, and HDL concentration in Mexican Americans. Diabetes 53, 2004, 2691-2695.

[13] Witkowska AM and Borawska MH. Soluble intercellular adhesion molecule-1 (sICAM-1): an overview. European Cytokine Network15, 2004, 91-98.

[14] Sacheck J. Pdiatric obesity: an inflammatory condition? J Parent and Enteral Nutri. 32(6) , 2008,633-637.

[15] Clinical Guidelines on the Identification, Evaluation, and Treatment of Overweight and Obesity in Adults-the Evidence Report. National Institutes of Health. Obes Res. 6 (suppl 2), 1998, 51S-209S

[16] Lustig RH and Weiss R. Disorders of energy balance. In: Sperling MA, editor. Pediatric Endocrinology. 3rd ed. Philadelphia (PA): Saunders Elsevier 2008, 788-838.

[17] The Expert Committee on the Diagnosis and Classification of Diabetes Mellitus. Follow-up report on the diagnosis of diabetes mellitus. Diabetes Care 26, 2003, 3160-3167.

[18] Trinder P. Determination of blood glucose using an oxidase-peroxidase system with a non-carcinogenic chromogen. J ClinPathol. 22(2), 1969,158-61.

[19] Buritus CA and Ashwood ER. Insulin measurements. In Buritus et al editors. Tietz Textbook of Clinincal Chemistry. Philadelelphia WB Saundon $2^{\text {nd }}$ ed ,1994,943-944.

[20] Matthews DR, Hosker JP, Rudenski AS, Naylor BA, Treacher DF and Turner RC. Homeostasis model assessment: insulin resistance and beta-cell function from fasting plasma glucose and insulin concentrations in man. Diabetologia. 28(7), 1985,412-9.

[21] Koch EA, Shan MR, Harlow LA, Louis RM., and Pope RM. Soluble intercellular adhesion molecule- 1 in arthritis. Clin. Immunol. Immunopathol. 71(2), 1994, 208-15.

[22] Tabibzadeh SS, Poubouridis D, May LT and Sehgal, PB. Interleukin-6 immunoreactivity in human tumors. Am. J. Pathol.135 (3), $1989,427-433$

[23] Sharma A, Artiss JD, Zak B. (1987) A method for the sequential colorimetric determination of serum triglycerides and cholesterol. ClinBiochem.; 20(3):167-72.

[24] Lopes-Virella MF, Stone P, Ellis S and Colwell JA (1977): Cholesterol determination in high-density lipoproteins separated by three different methods. ClinChem; 23: 882-884.

[25] Rifai N, Warnick GR, McNamara JR, Belcher JD, Grinstead GF and Frantz ID. Measurement of low-density-lipoprotein cholesterol in serum: a status report.Clin Chem. 38, 1992, 150-160.

[26] Iamopas O, Chongviriyaphan N and Suthutvoravut U. Metabolic syndrome in obese Thai children and adolescents. J Med Assoc Thai. 94(3), 2011,S126-32.

[27] Eckel RH, Grundy SM and Zimmet P. The metabolic syndrome. Lancet. 365, 2005,1415-1428.

[28] Morrison JA, Glueck CJ, Horn PS, Schreiber GB and Wang P. Homeostasis model assessment of insulin resistance*body mass index interactions at ages 9 to 10 years predict metabolic syndrome risk factor aggregate score at ages 18 to 19 years: a 10 -year prospective study of black and white girls : Metab.58(3), 2009,290-5.

[29] Keskin M, Kurtoglu S, Kendirci M, Atabek ME and Yazici C. Homeostasis model assessment is more reliable than the fasting glucose/insulin ratio and quantitative insulin sensitivity check index for assessing insulin resistance among obese children and adolescents. Pediatr.115, 2005,e500-e503.

[30] D'Adamo E, Impicciatore M, Capanna R, LoredanaMarcovecchio M, Masuccio FG, Chiarelli F and Mohn AA. Liver steatosis in obese prepubertal children: a possible role of insulin resistance. Obesity 16, 2010,677-683.

[31] Jiménez MV, Rosario MartosEstepa RM, Camacho RM, EstradaRC, Luna FC and Guitarte FB. Endothelial dysfunction is related to insulin resistance and inflammatory biomarker levels in obese prepubertal children. Europ J Endocrinol.156 (4) ,2007, 497-502. 
[32] Sonya V Galcheva, Violeta M Iotova, Yoto T Yotov, SergioBernasconi and Maria E Street. Circulating proinflammatory peptides related to abdominal adiposity and cardiometabolic risk factors in healthy prepubertal children. European Journal of Endocrinology $164,2011,553-558$.

[33] Olza J, Aguilera CM, Gil-Campos M, Leis R, Bueno G, Valle M, Cañete R, Tojo R, Moreno LA and Gil A.Waist-to-height ratio, inflammation and CVD risk in obese children. Public Health Nutr.17(10), 2014,2378-85.

[34] Valle M, Martos R, Cañete MD, Valle R, van Donkelaar EL, Bermudo F, Cañete R.(2015):Association of serum uric acid levels to inflammation biomarkers and endothelial dysfunction in obese prepubertal children . Pediatr Diabetes; 16(6):441-7.

[35] Oliveira AC, Oliveira AM, Adan LF, Oliveira NF, Silva AM andLadeia AM. C-reactive protein and metabolic syndrome in youth: a strong relationship? Obesity. 16(5),2008,1094-8.

[36] Semiz S, Rota S, Edema O, Ozdemir A and Kaptanoğlu B. Are C-reactive protein and homocysteine cardiovascular risk factors in obese children and adolescents? : Pediatr Int.50(4),2008,419-23.

[37] Sasaki Y1, Takeda H, Sato T, Orii T, Nishise S, Nagino K, Iwano D, Yaoita T, Yoshizawa K, Saito H, Tanaka YandKawata S. Serum Interleukin-6, insulin, and HOMA-IR in male individuals with colorectal adenoma.Clin Cancer Res.18(2),2012,392-9.

[38] Bosanská L, Michalský D, Lacinová Z, Dostálová I, Bártlová M, Haluzíková D, Matoulek M, Kasalický M and Haluzík M.The influence of obesity and different fat depots on adipose tissue gene expression and protein levels of cell adhesion molecules. Physiol Res.;59(1), 2010,79-88.

[39] Norata GD, Grigore L, Raselli S, Seccomandi PM, Hamsten A, Maggi FM, Eriksson P and Catapano AL. Triglyceride-rich lipoproteins from hypertriglyceridemic subjects induce a pro-inflammatory response in the endothelium: Molecular mechanisms and gene expression studies. J Molec Cell Cardiol. 40,2006, 484-494.

[40] Hulthe J, Wikstrand J, Mattsson-Hulten L \& Fagerberg B. Circulating ICAM-1 (intercellular cell-adhesion molecule 1) is associated with early stages of atherosclerosis development and with inflammatory cytokines in healthy 58 -year-old men: the Atherosclerosis and Insulin Resistance (AIR) study. Clinical Science (Lond) 103, 2002, 123-129.

[41] Ziccardi P, Nappo F, Giugliano G, Esposito K, Marfella R, Cioffi M, D'Andrea F, Molinari AM \&Giugliano D. Reduction of inflammatory cytokine concentrations and improvement of endothelial functions in obese women after weight loss over one year. Circulation 105, 2002, 804-809.

[42] Desideri G, De Simone M, Iughetti L, Rosato T, Iezzi ML, Marinucci MC, Necozione S and Ferri C. Early activation of vascular endothelial cells and platelets in obese children. J ClinEndocrinolMetabol. 90,2005, 3145-3152.

[43] Lawlor DA, Benfield L, Logue J, Tilling K, Howe LD, Fraser A, et al. Association between general and central adiposity in childhood, and change in these, with cardiovascular risk factors inadolescence: prospective cohort study. BMJ. 341, $2010, \mathrm{c} 6224$.

[44] Chang CJ, Jian DY, Lin MW, Zhao JZ, Ho LTandJuan CC. Evidence in obese children: contribution of hyperlipidemia, obesityinflammation, and insulin sensitivity.PLoS One26, 2015,10(5):e0125935. 